\title{
Tissue reaction and surface morphology of absorbable sutures after in vivo exposure
}

\author{
Miguel G. S. Andrade · Ruben Weissman • \\ Sílvia R. A. Reis
}

Received: 10 January 2005 / Accepted: 21 October 2005

(C) Springer Science + Business Media, LLC 2006

\begin{abstract}
Tissue reaction to suture materials depends mainly on how the polymer they are composed of interacts with the tissues. There are few in vivo studies evaluating the suture material modifications resulting from its interaction with tissues. This paper aimed to study rat subcutaneous tissue reaction to irradiated polyglactin 910 , polydioxanone, poliglecaprone 25 and chromic gut and its correlation with the ultra-structural alterations the materials undergo. The histological alterations were studied on the 1st, 2nd, 3rd, 7th and 14th day after suture implantations. In these periods, the materials were removed from the tissues and their surfaces were analyzed by scanning electron microscopy. Irradiated polyglactin 910 stimulated the formation of multinucleated giant cells and its filaments underwent cleavage and dissolution. In potydioxanone, a few inflammatory cells and scar fibrosis was observed, and triangular cracks appeared on its surface. Around the poliglecaprone 25, a diffused infiltration of a few mononuclear cells and fibrosis was recorded and formation of craters was observed on its surface. Chromic gut induced necrosis and granulation tissue and underwent dissolution in the tissues during the studied periods. In this study, it was observed that suture materials induced differentiated tissue reactions and morphologic surface changes, suggesting that indications should be individualized.
\end{abstract}

M. G. S. Andrade $(\bowtie) \cdot$ R. Weissman

Post-graduation Program on Oral and Maxillofacial Surgery and Traumatology, Catholic University of Rio Grande do Sul, Brazil

S. R. A. Reis

Diagnosis and Therapeutic Department, Federal University of Bahia, Brazil

\section{Introduction}

Natural suture materials were the first materials used in synthesis maneuvers, but have fallen into disuse because of the pronounced inflammation they induce, and monofilament, synthetic, absorbable materials that present better biological behavior are preferred [1,2].

The physical and chemical nature of suture materials interferes with tissue reaction as well as with its degradation. Therefore, several initiatives were introduced to control these processes. The most notable among them were: to change one of the monomers of the polymer [3], suture material impregnation with glycerin or silver $[4,5]$ and polymer exposure to gamma irradiation [6].

Irradiated polyglactin 910 is a polyester copolymer made from glycolide and lactide. The irradiation the polymer is exposed to involves an extensive chain scission [7]. As a result, the increased chain end density reduces the molecular weight of the suture $[7,8]$ and generates a large number of free radicals, which facilitates reaction with water, leading to its cleavage and consequently, to its increased susceptibility to biodegradation. This process therefore, accelerates the absorption rate [7], essentially completed at 42 days, and its tensile strength is prematurely lost [8]. Thus, this suture should not be used where tissues are under stress.

The absorption process of polydioxanone, a homopolymer made from $\rho$-dioxanone [9], is slower than that of other suture material hydrolysis, due its chemical structure [10] and to its monofilamentary aspect [11]. Surface alterations occur later, proving the great tensile strength of the material, which is comparable with that of non-absorbable suture [12].

In the case of poliglecaprone 25 , the association between $\varepsilon$-caprolactone and glycolide makes it more hydrophilic than other suture materials containing $\varepsilon$-caprolactone, such as, $\mathrm{P}(\mathrm{LA} / \mathrm{CL})$ in which $l$-lactide substitutes glycolide $[3,13]$. 
However, its absorption occurs at a slow rate and is completed in 91 to 119 days [9]. In vitro exposure of this material to a peroxide and superoxide rich solution, propitiates the appearance of craters on its surface, suggesting that these alterations would also appear during the time poliglecaprone 25 stays within inflamed tissues [13].

Chromic gut is composed of collagen derived from the serosal layer of beef or fibrous submucosal layer of sheep and coated with a chromic salt solution. Its degradation results from the collagen enzymatic digestion, which is completed in 60 days [14]. This suture material is considered to be the ideal suture for the urinary tract [15].

Suture material surface morphology analysis is limited to in vitro studies $[8,11,13,16]$, in which these materials were exposed to different solutions. Only Okada, Hayashi and Ikada (1992) [14] evaluated chromic gut surface in an in vivo study, using scanning electron microscopy to analyze the material surface morphology after its implantation in rabbit subcutaneous tissue. It therefore becomes particularly relevant to study the alterations undergone by irradiated polyglactin 910 , polydioxanone, poliglecaprone 25 and chromic gut after interaction with tissues.

In this research, the histological alterations of the tissues surrounding these sutures after their implantation in rat subcutaneous tissue were investigated. Scanning electron microscopy propitiated the analysis of surface alterations that tissue modifications promoted in these materials.

\section{Materials and methods}

Twenty male Wistar, albino rats, weighing 200 to $250 \mathrm{~g}, 70$ to 90 days old, bred and kept under sanitary conditions in a conventional vivarium, were used. During the experiment, the animals were fed with balanced feed and water add libitum in accordance with bioethics criteria about the protection of animals used in researches.

After sedation with ether, rats were anesthetized with an intramuscular injection of a mixture of tiletamine and zolazepam. Next, the rats' backs were shaved and asepsis of the skin was performed. Irradiated polyglactin 910 (Coated Vicryl Rapid ${ }^{\circledR}$ ), polydioxanone (PDS II ${ }^{\circledR}$ ), poliglecaprone 25 (Monocryl ${ }^{\circledR}$ ) and chromic gut (Chromic Gut ${ }^{\circledR}$ ) (Ethicon, Inc. product, Sommerville, NJ), diameter 4-0, were implanted in the subcutaneous tissue of the rats' backs using a needle that transfixed the epidermis and dermis in the laterolateral direction.

The different sutures were arranged in a craniocaudal sequence in the following randomized order: Coated Vicryl Rapid ${ }^{\circledR}$, Monocryl ${ }^{\circledR}$, PDS II ${ }^{\circledR}$ and Chromic Gut ${ }^{\circledR}$, at a distance of $1 \mathrm{~cm}$ from each other. After implantation, the excess suture material was cut next to the needle entry and exit points and the skin was massaged to assure that the material was interred.

The rats were distributed into five experimental groups represented by the death rate, which occurred after 24,48 , 72 hours, and on the 7th and 14th days. When death was confirmed, four skin fragments containing each suture material were obtained, and subsequently fixed in a $10 \%$ formalin solution. After 24 hours, the suture material that had been implanted was removed and the tissues were submitted to routine histological processing. The histological sections were stained by hematoxylin and eosin. The removed sutures were dried and submitted to scanning electron microscopy. Four fragments of the original above-mentioned materials that had not been implanted in tissues, comprised suture control groups, in order to study their original surfaces.

All the suture samples were mounted on metal stubs and coated with a gold alloy. The scale used was $100 \mu \mathrm{m}$ and the electron acceleration tension was $15 \mathrm{kV}$.

\section{Results}

When the suture material, previously implanted in tissues, was being removed, some differences were observed in the material behavior. For all the monofilament sutures, represented by chromic gut, polydioxanone and poliglecaprone 25 , the fragment that had been implanted was easily removed from tissues and prepared for scanning electron microscopy. Therefore, in the histological sections corresponding to tissue reaction to monofilament sutures, no material remainders were observed in tissues. With regard to the implanted braided suture material, irradiated polyglactin 910, it offered some resistance to being removed from tissues. In these observation subgroups, ultra-structural analysis was performed on the suture material fragments that were removed from tissues after delicate tractioning. Thus, in the histological section corresponding to irradiated polyglactin 910, remnants of suture material were noted in tissues. This result was observed in two rats on the 1st day of implantation, two on the 2 nd, two on the 3 rd, three on the 7 th day and in all rats on the 14th day of implantation.

\subsection{Irradiated polyglactin 910}

\subsubsection{Histological analysis}

On the first two days after implantation, the inflammatory reaction at the margins of the sutures was minimal and was characterized by a few polymorphonuclear leukocytes that were distributed between the filaments in some rats. Granulation tissue and macrophages were irregularly distributed and observed in an incipient way on the 3rd day. Only on the 7 th postimplantation day, was a small space of the material 
filled by granulation tissue. A peculiar finding of this material was the presence of multinucleated giant cells as from the 7th to 14th day of the experiment (Fig. 1A and Fig. 1B). At that point, a fibrous connective tissue slowly began to substitute the granulation tissue (Fig. 1C).

\subsubsection{Ultra-structural analysis}

On the surface of the irradiated polyglactin 910 suture used as a control, it was observed that the filaments were organized in helicoidally distributed groups forming a crisscross, and that they were coated with an interposed amorphous material (Fig. 2A). Within the first 24 hours after implantation, the filaments were already individualized as a result of the fast absorption of the coating. At this moment, some of them presented curvatures that increased by the 3 rd day, owing to randomly dispersed perpendicular fractures. On the 7th day, the filaments began to dissolve (Fig. 2B) and this process was more accentuated on the 14th day, when the crisscross of the groups of filaments became imperceptible (Fig. 2C).

\subsection{Polydioxanone}

\subsubsection{Histological analysis}

On the 1st day, the tissue was characterized by the presence of a discreet eosinophilic band representing coagulation necrosis. In one rat it was possible to identify focal areas of edema. The collagen fibers adjacent to the necrotic tissue were organized. On the 2 nd day, the appearance of neutrophils was detected. A mild infiltration of mononuclear cells (Fig. 3A) was observed on the 3rd day after implantation as well as in some rats, where focal areas of necrosis were still present. Only on the 7th day of the study, was granulation tissue observed. At this stage, collagen fibers began to be deposited in the area. Mature fibroblasts were found dispersed within these fibers. On the 14th day, the granulation tissue around the material was substituted by fibrous tissue, whose collagen fibers had a parallel disposition (Fig. 3B).

\subsubsection{Ultra-structural analysis}

The polydioxanone surface, used as a control, was comprised of striations distributed parallel to its axis (Fig. 4A). No alterations in surface morphology were observed on the 1st, 2nd, 3rd (Fig. 4B) or 7th days of implantation. Only on the 14th day of the study, were morphology changes observed on its surface, as the material exhibited triangular cracks (Fig. 4C). Where these alterations were concentrated, a zigzag pattern was noticed.

\subsection{Poliglecaprone 25}

\subsubsection{Histological analysis}

The reaction induced by poliglecaprone 25 on the 1 st day was similar to that of polydioxanone. But, on the 2nd day, a diffuse infiltration of a few lymphocytes among the fibers was noticed (Fig. 5A). On the 3rd post-implantation day, a mild granulation tissue was present associated with a smaller population of inflammatory cells. The fibers began to organize themselves on the 7th day, amid a granulation tissue in a continuous arrangement along the interface that contained macrophages. Scar tissue with elongated fibroblasts was formed on the 14th day (Fig. 5B) in a more sporadic manner when compared with those surrounding polydioxanone.

\subsubsection{Ultra-structural analysis}

Of all the control suture materials analyzed, poliglecaprone 25 exhibited the most regular surface (Fig. 6A). On the first two days, crater-shaped areas appeared (Fig. 6B) and they increased in number and diameter on the 3rd day. On the 7th day, the cavities coalesced and this characteristic became more evident on the 14th day (Fig. 6C).

\subsection{Chromic gut}

\subsubsection{Histological analysis}

During the first 24 hours after suture material implantation, tissue necrosis was observed and it became thicker and infiltrated by neutrophils after 48 hours (Fig. 7A). The formation of granulation tissue, characterized by fibroblasts, was already observed after 72 hours. Lymphocyte leakage and vascular congestion were recorded. On the 7th day the tissue presented lymphocytes, but some fibroblasts were present. Collagen fibers began to be organized amid granulation tissue surrounding the material. The cellular poplation consisted of mature fibroblasts on the 14th day. At this point, the fibers were still loosely distributed in spite of being more numerous. The granulation tissue was still present (Fig. 7B).

\subsubsection{Ultra-structural analysis}

The original chromic gut surface was covered by randomly distributed fusiform structures (Fig. 8A). During the first 72 hours after implantation, the surface was populated by cells (Fig. 8B). From the 3rd day on, a line bordered the suture surface, becoming more evident on the 7th day. From the 14th day onward, that line was attenuated (Fig. 8C). As from the 7th day, absence of cells and coating was observed. 
Fig. 1 Coated Vicryl Rapid ${ }^{\circledR}$. Presence of multinucleated giant cells (arrows) between the filaments of suture material at seven post-implantation days (A) Multinucleated giant cells (arrows) at the margins of the suture seven days after implantation (B). Connective fibrous tissue $(*)$ between the filaments on the 14th day (C). Hematoxylin and eosin stain.

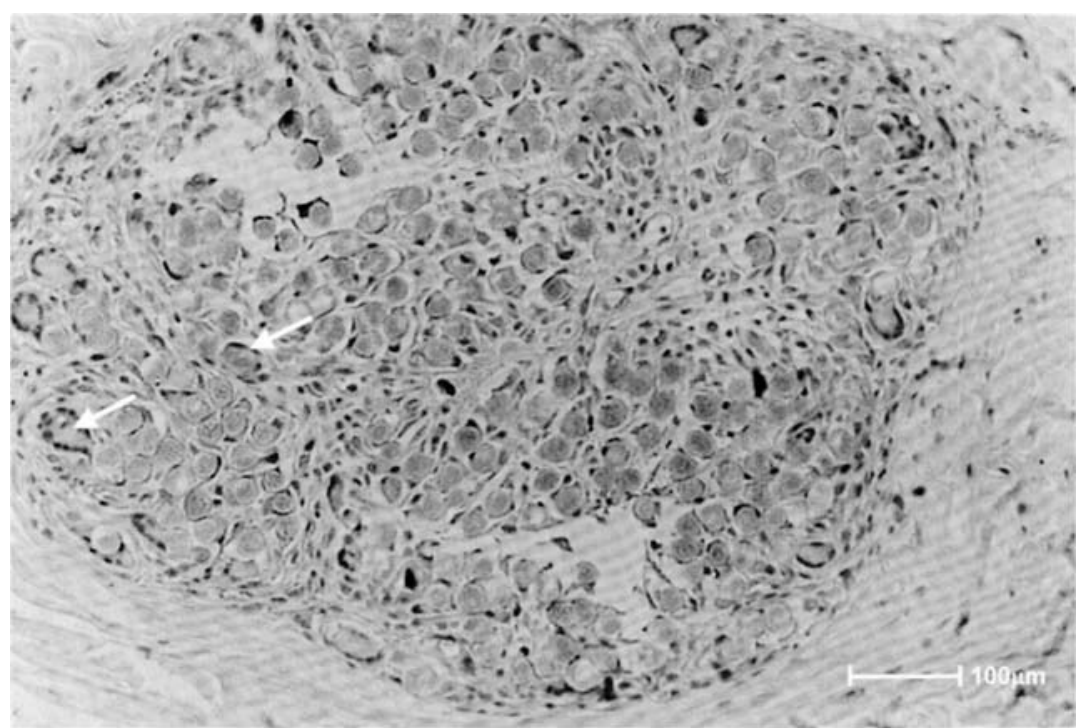

(a)

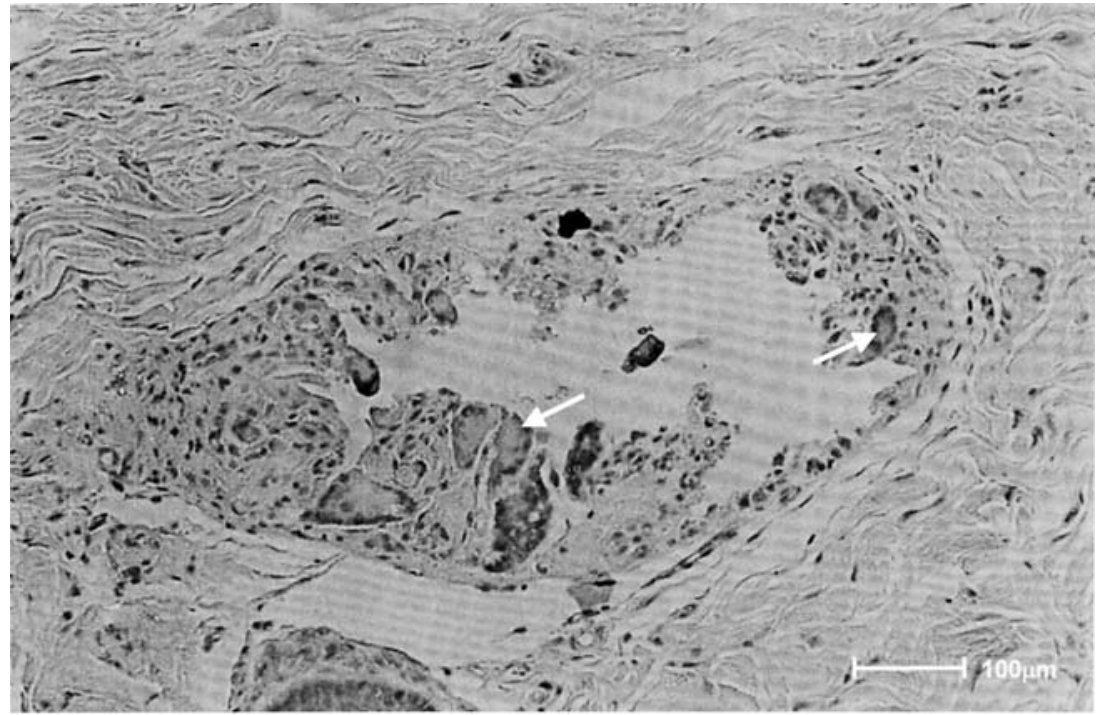

(b)

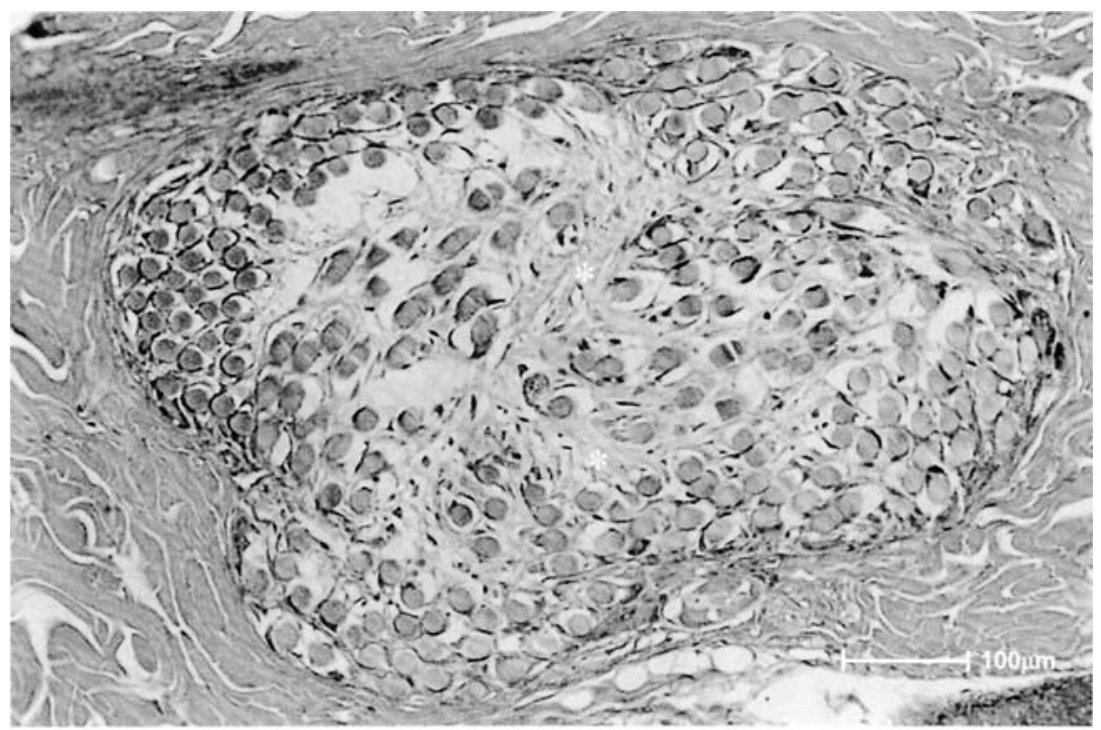

(c) 
Fig. 2 Coated Vicryl Rapid ${ }^{\circledR}$. The scanning electron micrograph showed the presence of amorphous material (arrows) coating the filaments of the original suture material (A). Beginning of the dissolution of the filaments on the 7th day of the experiment (B). Wide dissolution of the material 14 days after implantation (C). Scale of $100 \mu \mathrm{m}$.

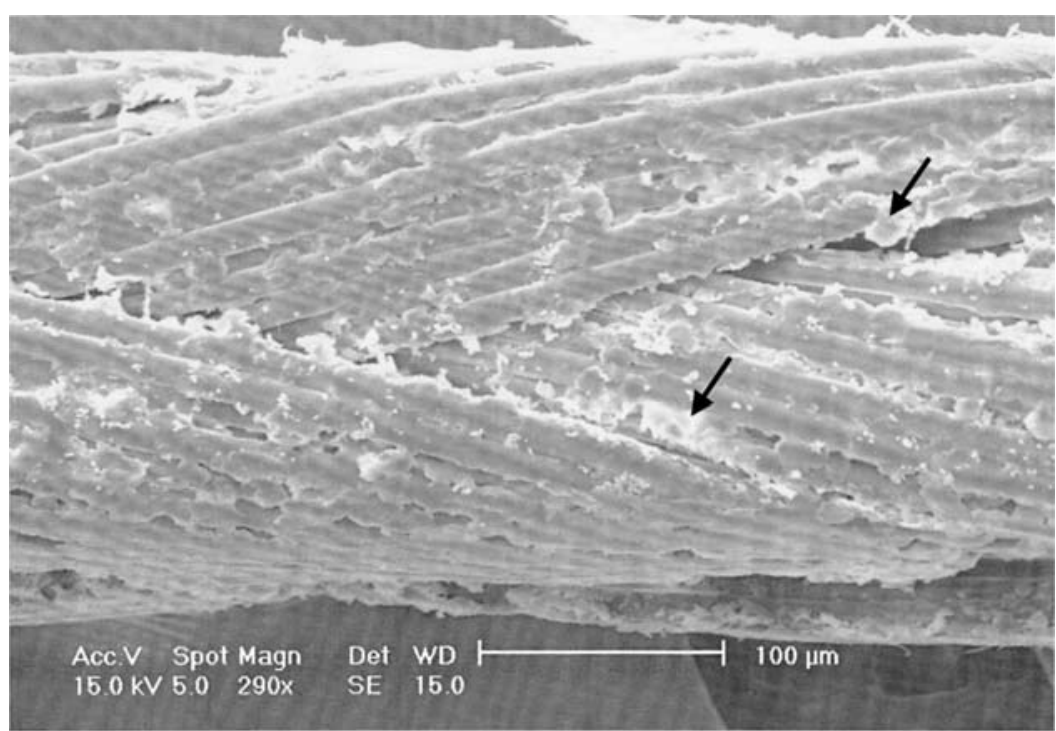

(a)

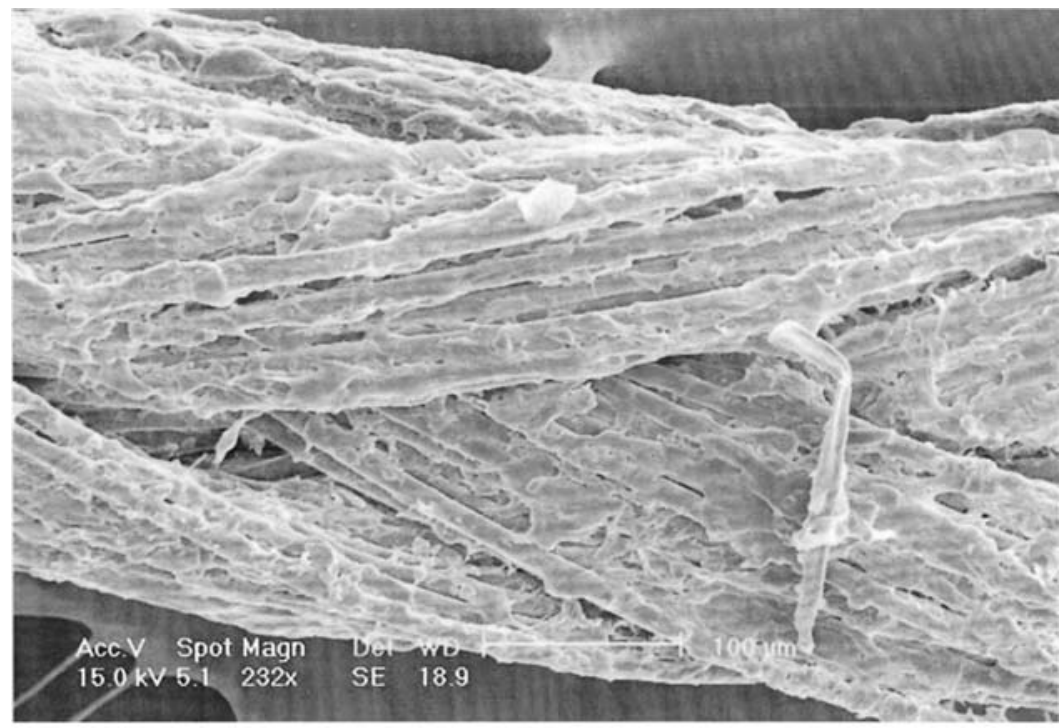

(b)

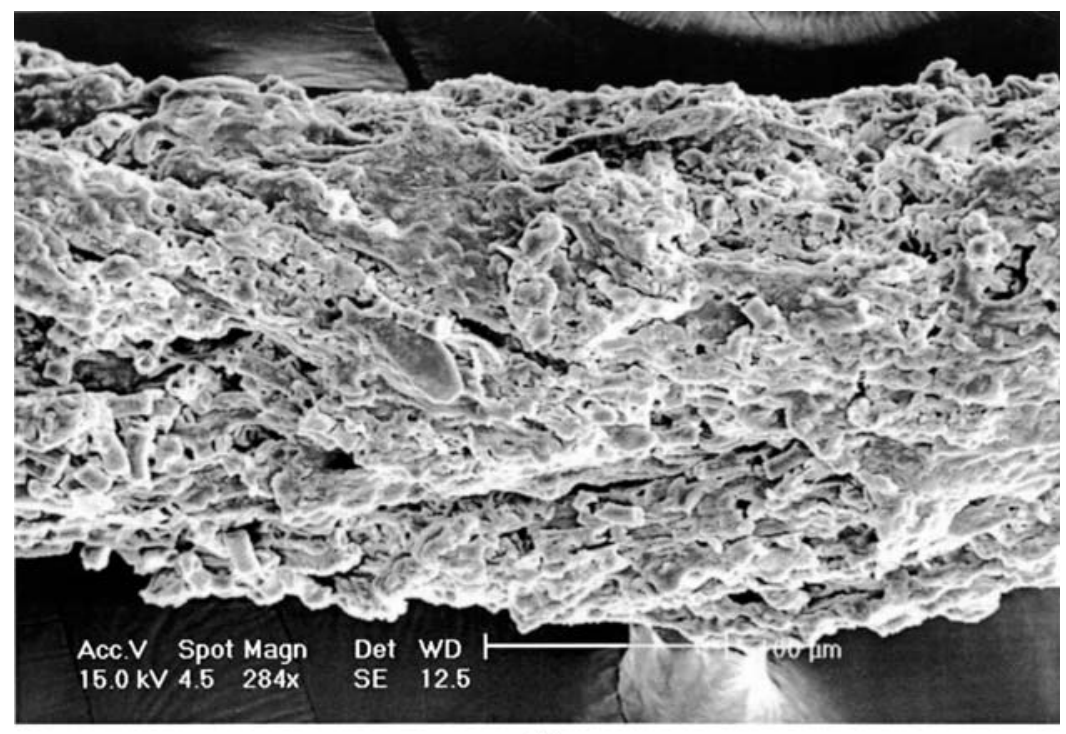

(c) 
Fig. 3 PDS II ${ }^{\circledR}$. Few

lymphocytes on the 3rd day of implantation (A). Presence of scar fibrosis $\left({ }^{*}\right)$ around the material on the 14th day (B). Hematoxylin and eosin stain.

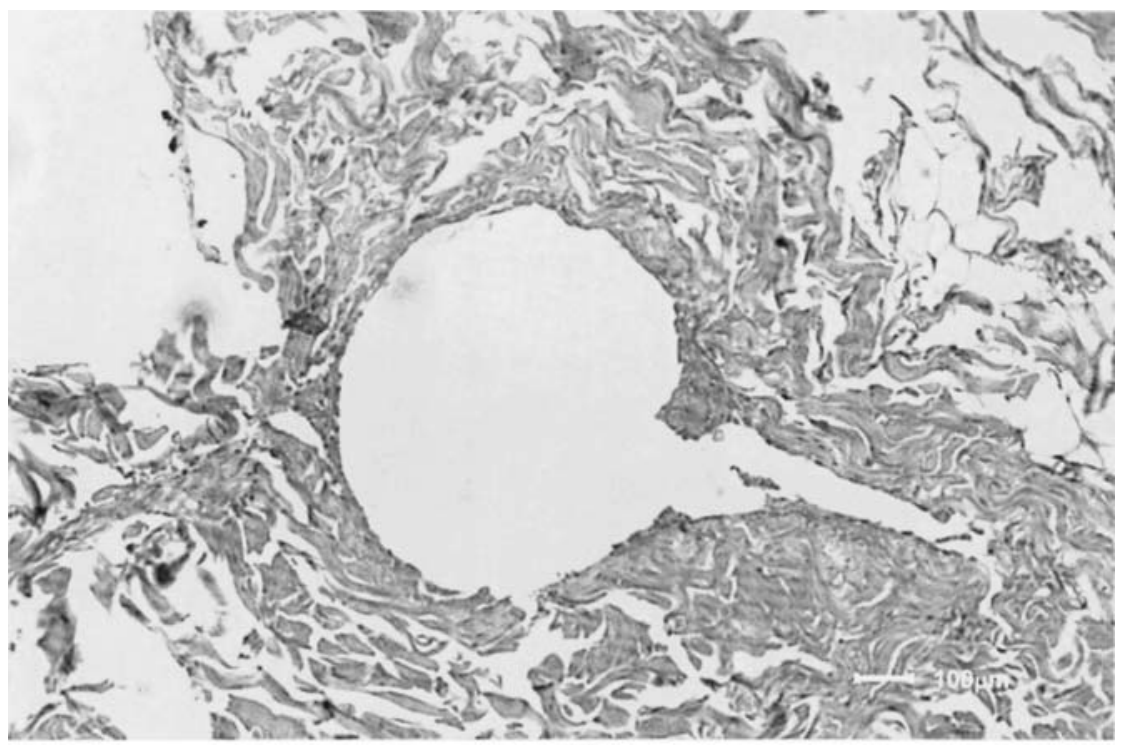

(a)

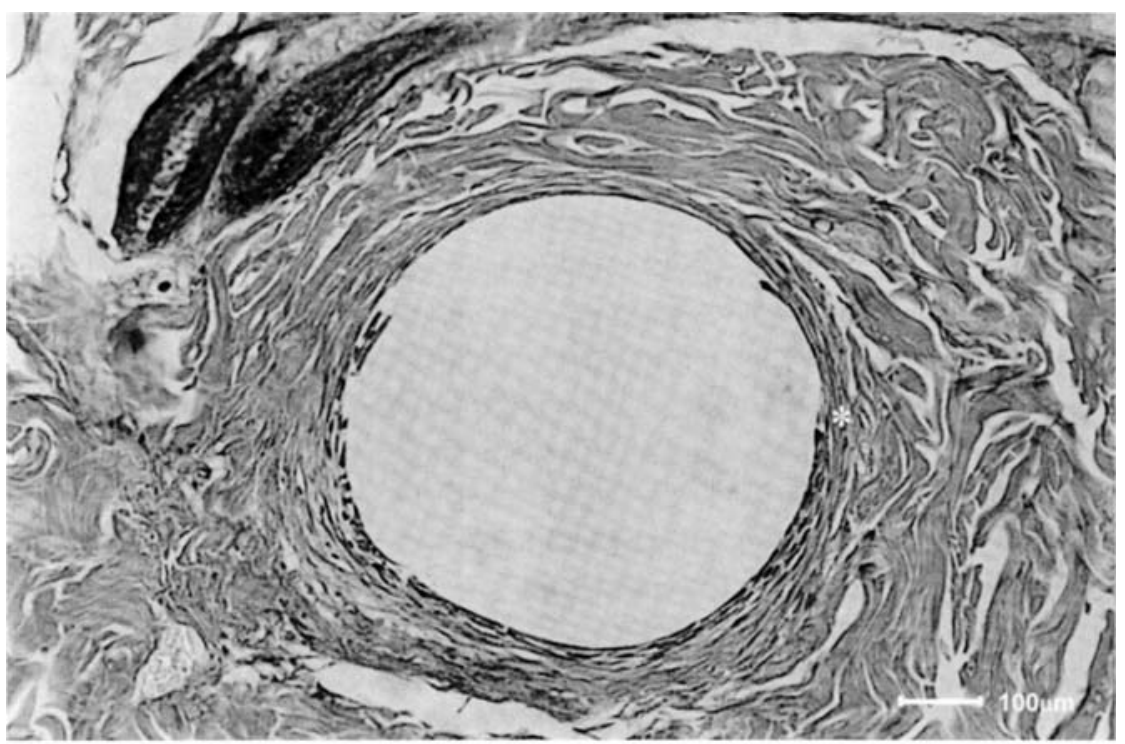

(b)

\section{Discussion}

The healing of a wound is a complex biological process controlled by several variables. The initial reaction of any tissue to suture results from the lesion induced by needle passage. The reaction to the polymers that comprise suture materials is subsequently established [17]. The purpose of this study was to evaluate how the subcutaneous tissue behaves in the presence of suture materials of different chemical natures. The methodology developed in this research eliminated the interference of the trauma related to incision and rupture. These surgical techniques were performed by most of the authors that studied this subject $[2,9,18,19,20]$. Therefore, by just using the passage of the needle, the sutures were implanted in the rat hypodermis. The inflammation formed in the tissues was connected with a reaction resulting from the suture polymer and from the transfixation prompted by the needle, which is inevitable when suture materials are used in synthesis techniques.

Irradiated polyglactin 910 was the only braided material analyzed in this study. Tissue reactions to this material differed from their reaction to the monofilament sutures analyzed. In the histological sections, the presence of multinucleated giant cells was observed after seven days of implantation, including the sections where no suture filament remnants were observed. Other authors also referred to the presence of this tissue reaction [21, 22]. This finding is justified by the ability of this polymer to induce an increase in the tumor necrosis factor synthesis by macrophages [23]. Under the influence of this cytokine action, immature 
Fig. 4 PDS II ${ }^{\circledR}$. The scanning electron micrograph revealed striations distributed parallel (arrows) to the control suture material axis (A). No surface alterations were present on the 3rd day (B). Triangular crack formation (arrows) was observed only 14 days after implantation (C). Scale of 100 $\mu \mathrm{m}$.

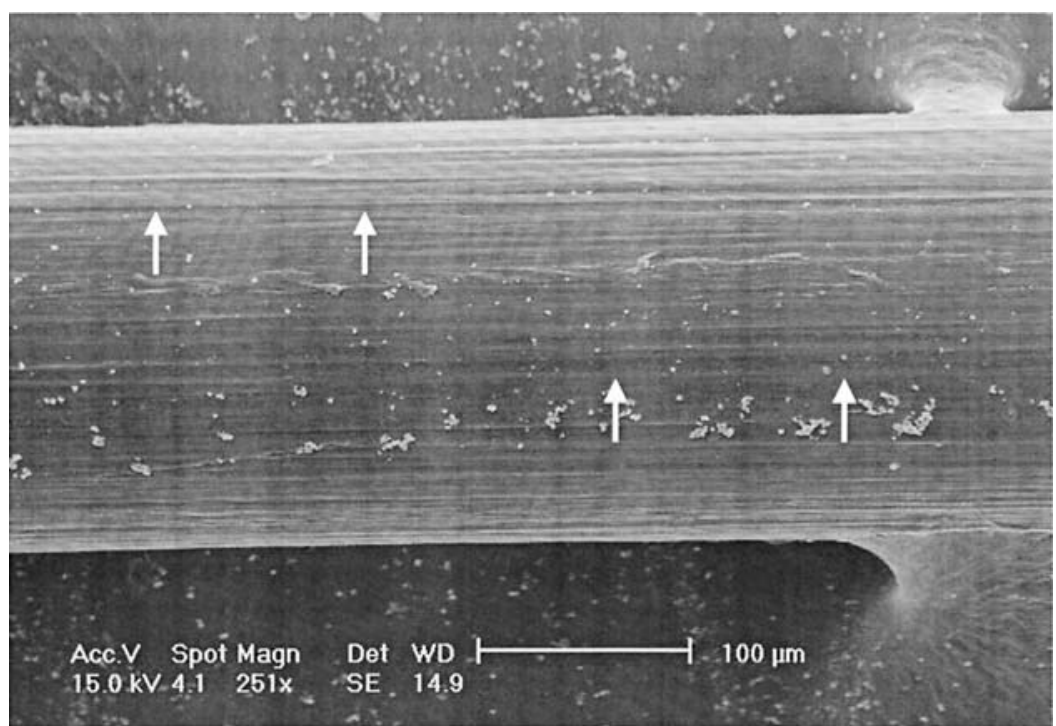

(a)

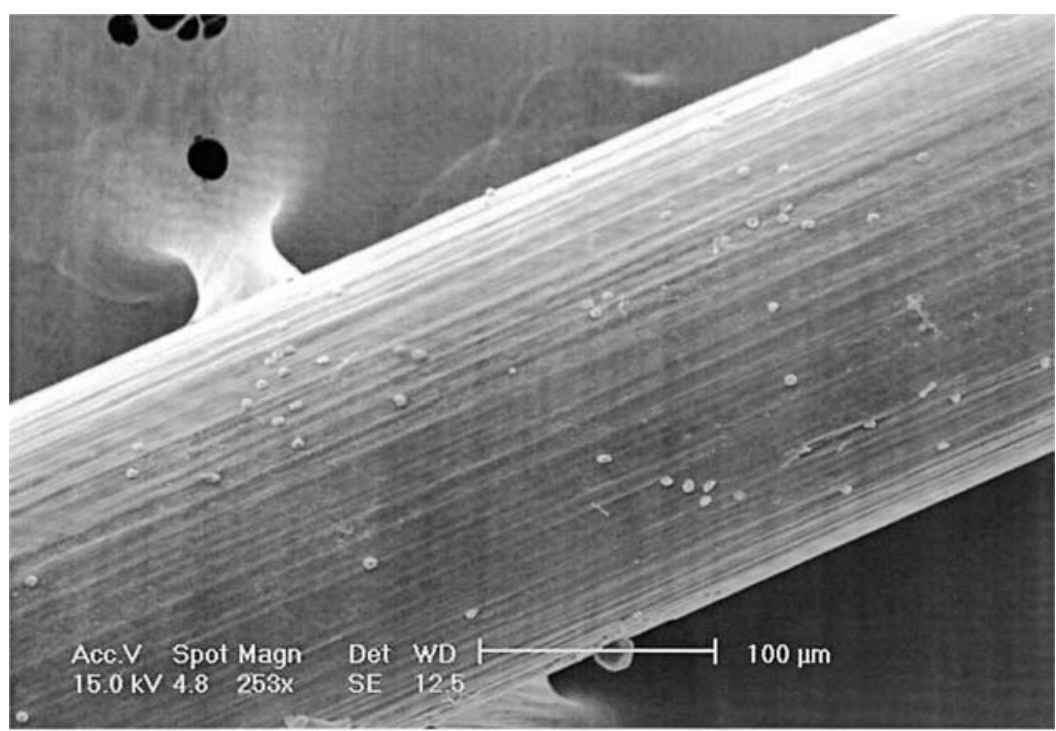

(b)

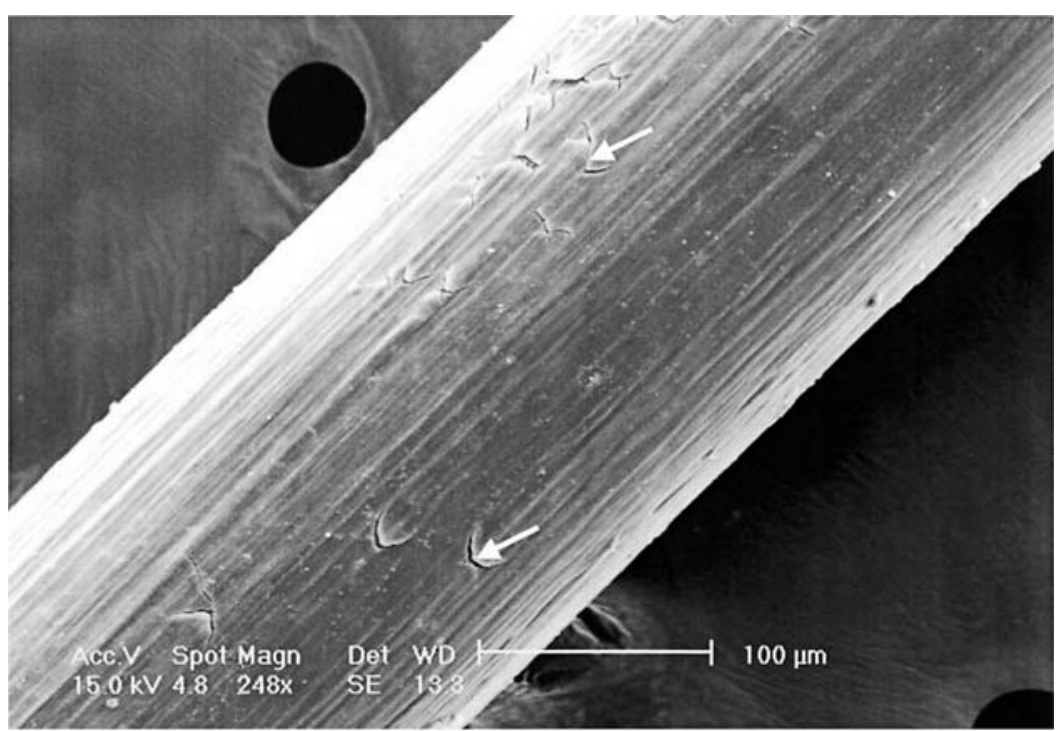

(c) 
Fig. 5 Monocryl ${ }^{\circledR}$. Diffuse infiltration of a few lymphocytes $\left(^{*}\right)$ on the 2nd day of implantation (A). Fibrosis $\left(^{*}\right)$ on the 14th day of the experiment (B). Hematoxylin and eosin stain, X200.

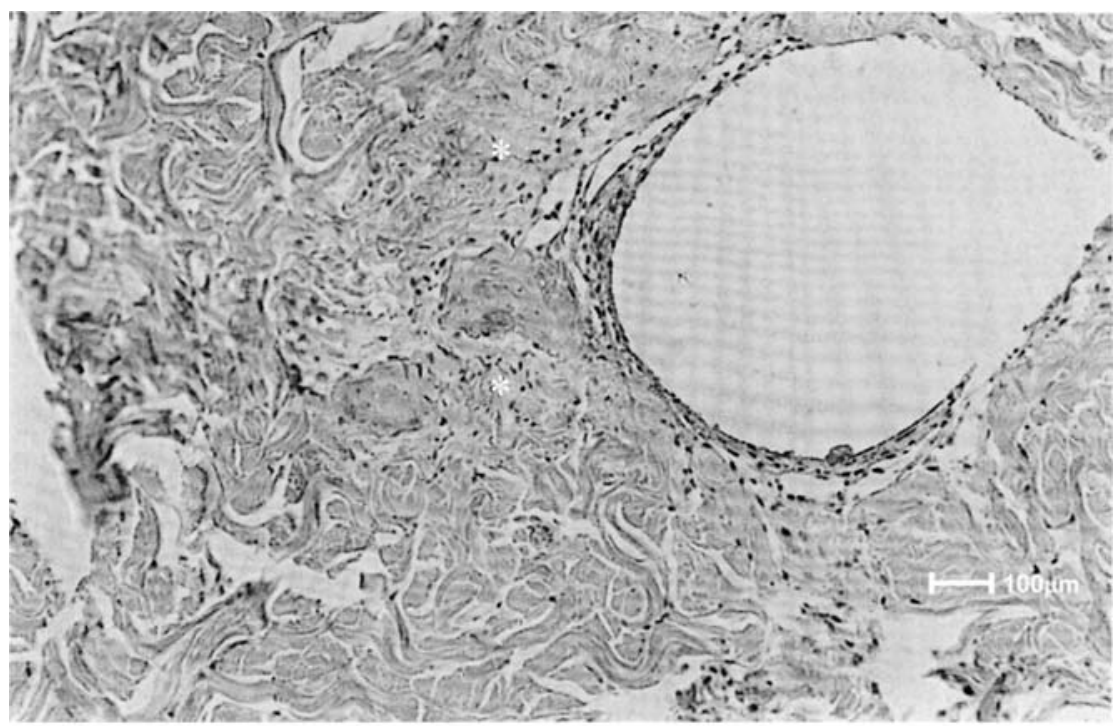

(a)

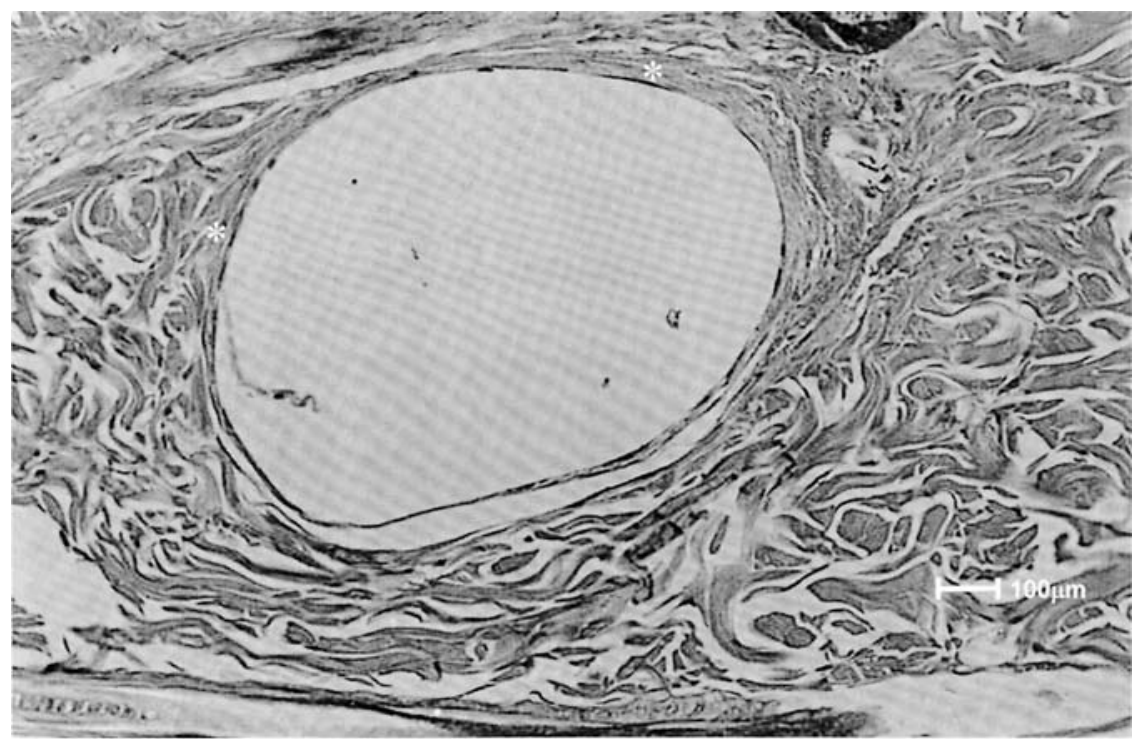

(b) macrophages change into epithelioid cells that build themselves to form giant cells. These cells influence the absorption of the material by releasing enzymes, peroxides and superoxide [13, 24].

The scanning electron microscopy analysis showed that the surface alterations in irradiated polyglactin 910, such as filament cleavage and curvature resulting from material hydrolysis began to occur from the 3rd day of implantation, and these alterations were more accentuated up to the 14th day. During this period, it was observed that parts of the polymer mass were still preserved. These findings contradicted Amato, Marcelli, Oreficci, Mastroianni and Vergnani (1991) [25] who studied the absorption process of this material in clinical research. According to these researchers, irradiated polyglactin 910 biodegradation is processed quickly with great tissue tolerability and only begins as from the 14 th day.

In the study of control sutures, it was found that the original irradiated polyglactin 910 surface is quite irregular, because of its multiple filaments. The suture is coated with a mixture composed of polyglactin 370 and calcium stearate to minimize the drag produced by the filaments during their passage through tissues [26]. This care in coating the material was, however, not enough to minimize the tissue alterations. The low molecular weight of the coating implies fast absorption within the tissues [27], allowing a better visualization of the filaments right from the 1st day. These findings were corroborated by other researches $[3,13]$.

On the 14th day, the wide dissolution undergone by irradiated polyglactin 910 , seen by scanning electron microscopy, 
Fig. 6 Monocryl ${ }^{\circledR}$. The scanning electron mcirograph showed the regular surface of the control sutrue material (A). Beginning of craters (arrows) at suture surface already on the 2nd day after implantation (B). Coalescence (arrows) of the cavities on the 14th day (C). Scale of $100 \mu \mathrm{m}$.

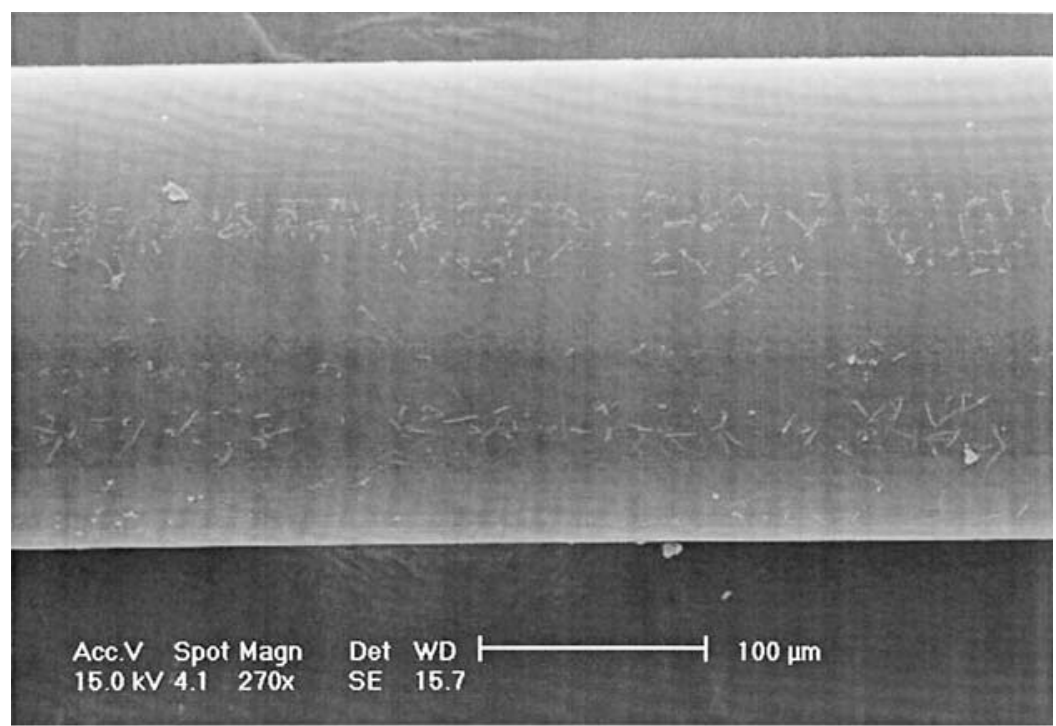

(a)
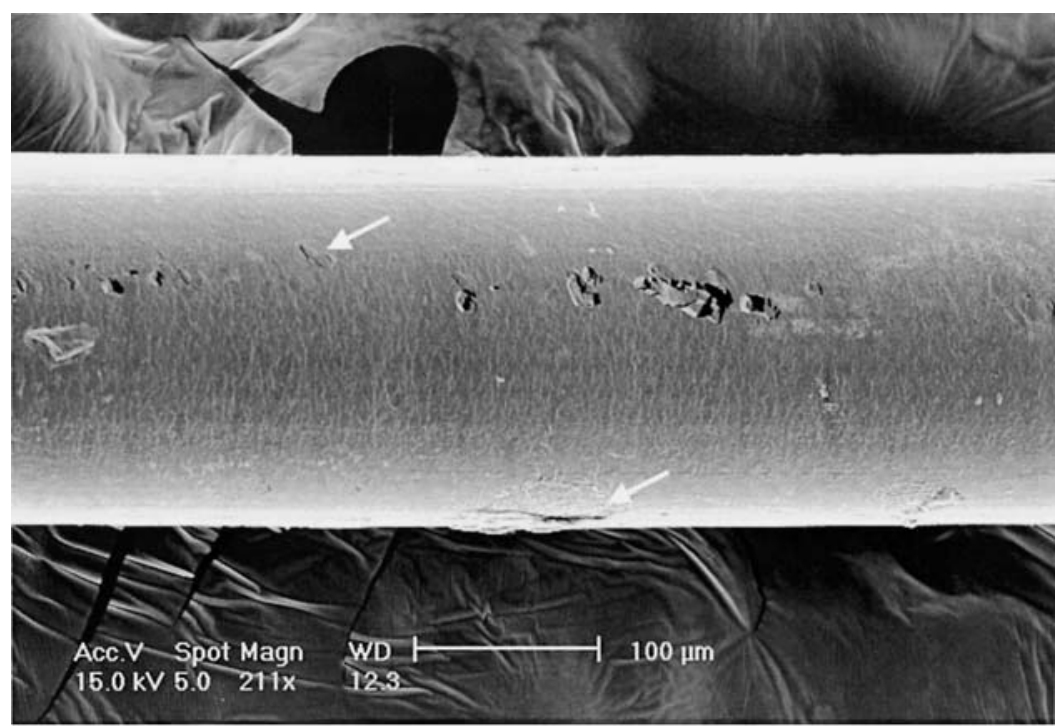

(b)
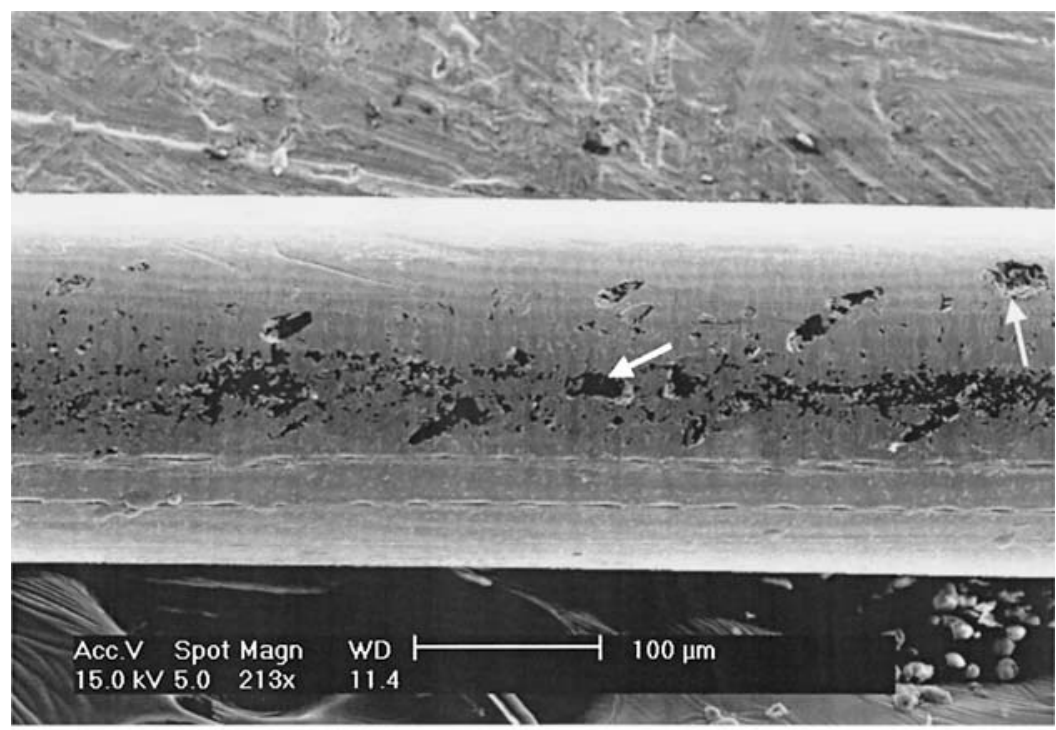

(c) 
Fig. 7 Chromic Gut ${ }^{\circledR}$. Necrosis (arrows) at tissue around the suture after two days of implantation (A). Granulation tissue $\left(^{*}\right)$ still present on the 14th post-implantation day (B). Hematoxylin and eosin stain, X200.

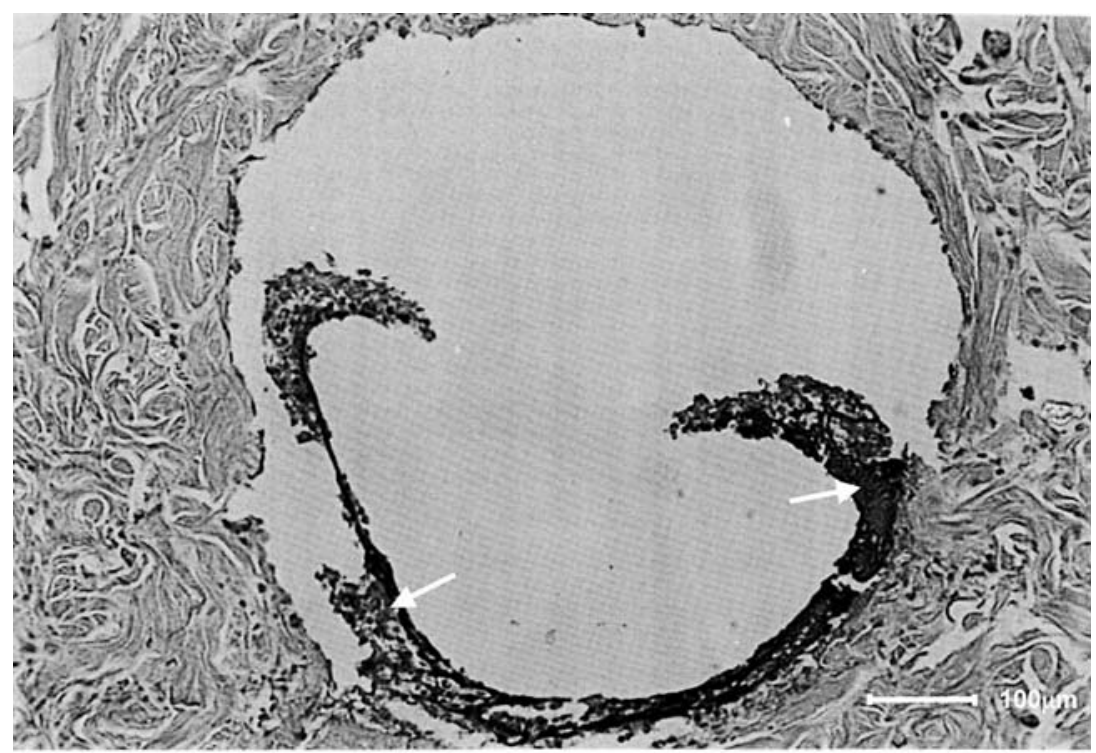

(a)

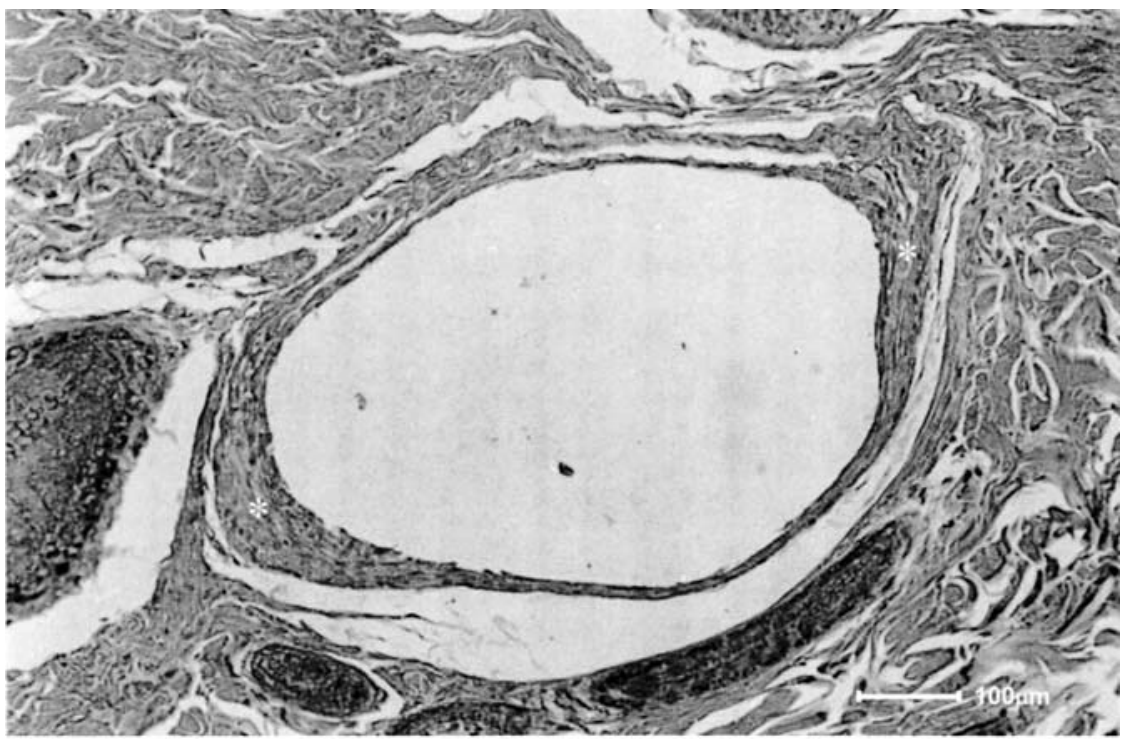

(b) confirms the impossibility of measuring the tensile strength of the material after 10 to 14 days of implantation in tissues [8, 28]. This result, associated with the histological alterations, such as the presence of collagen fibers among the filaments, confirms the difficulty, found in this research, of removing the fiber from tissues in some rats.

The alterations relative to polydioxanone absorption only occurred at 14 days of implantation and even so, did not involve the fiber core, showing that the polymer structure was kept relatively uniform during the studied period. According to Sabino, González and Marquez (2000) [11] the cracks found occur in the amorphous region of the polymer and provide an opening for water diffusion inside the filament that affects the crystalline region. These aspects demonstrate the slow material absorption process [27], evidenced by the small amount of ester groups in the polydioxanone chain $[10,11]$.

The mild inflammatory reaction observed in the histological sections of this suture also confirms the fine alterations found on its surface, corroborating the role that inflammation plays in hydrolysis. Scar tissue was very organized around this suture material and collagen fibers were arranged parallel to it in a condensed way. These findings are in agreement with other researchers [18].

In the poliglecaprone 25 study, it was observed that infiltration of mononuclear cells was not limited to the material interface, and they were dispersed among the collagen fibers. It has been demonstrated [23], in vitro, that polymers from suture materials release soluble factors that activate macrophages to cytokine synthesis. In this material, 
Fig. 8 Chromic Gut ${ }^{\circledR}$. The scanning electron microscopy analysis revealed that several fusiform structures (arrows) provided an irregular aspect to the surface of the control material (A). On the 2nd day many cells populated the suture surface (B). On the 14th day, the line (arrows) at the material surface was attenuated (C). Scale of $100 \mu \mathrm{m}$.

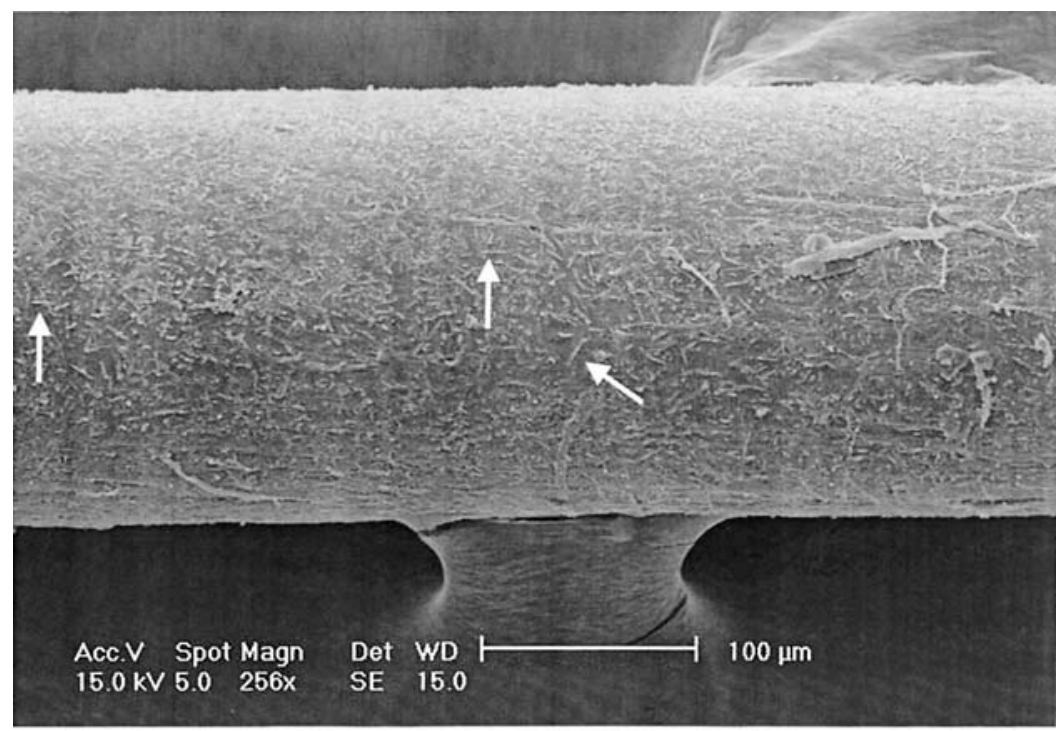

(a)

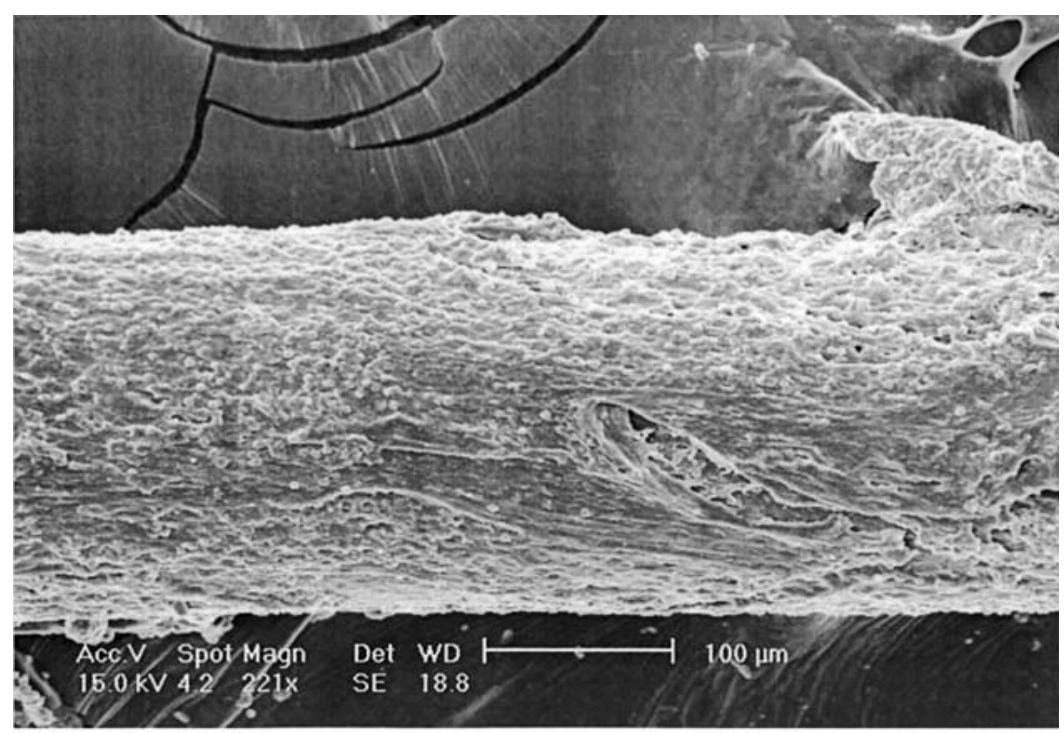

(b)
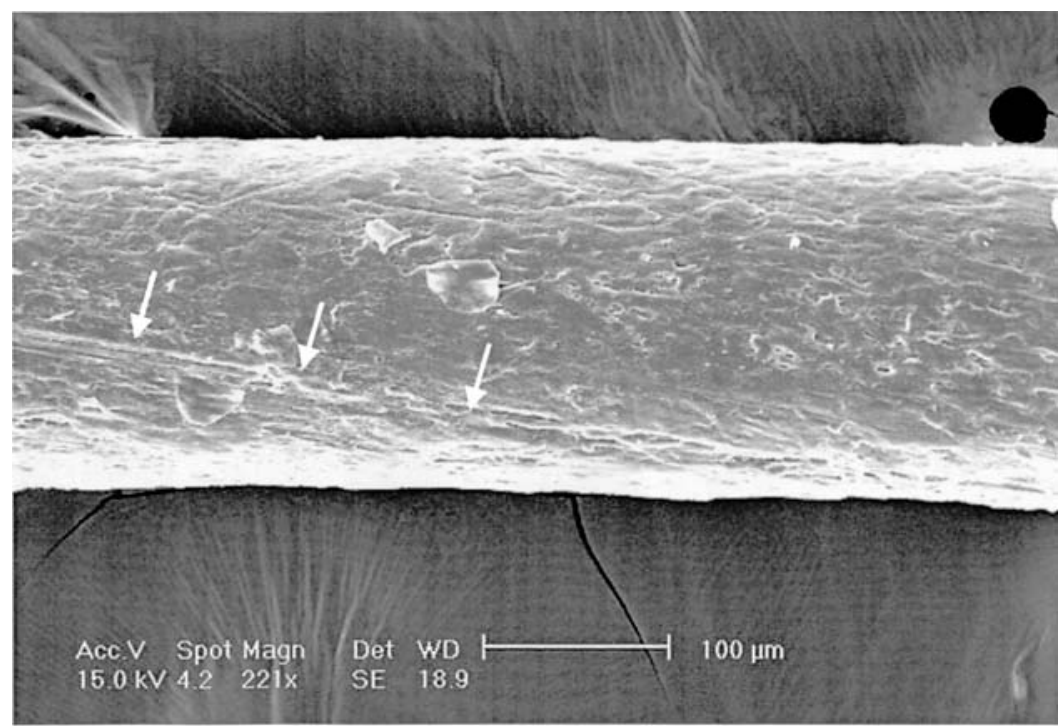

(c) 
the $\varepsilon$-caprolactone has an excellent solvent affinity and makes poliglecaprone 25 a suture very vulnerable to biodegradation. $[3,13]$. Thus, its oligomers spread quickly in the tissue, stimulating lymphocyte chemotaxis to a more distant area. Furthermore, crater formation on the suture as from the 1st day, confirms larger monomer release in the tissue. These craters, also found by other researchers [13], possibly result from the action of tissue esterases synthesized by inflammatory cells [1]. Therefore, all the characteristics pertinent to this material intensify its absorption process. In spite of the surface alterations having increased during the experiment, no diffuse infiltration of cells was observed on the following days after implantation. This is explained by the more accentuated neovascularization around the suture, which increased the number of vessels in the area providing the absorption of metabolites from poliglecaprone 25 . This fast metabolite absorption was confirmed in a study [8] on poliglecaprone 25 pharmacokinetics using radioactive polymers, which demonstrated the absorption of $8 \%$ of the material in the first week after implantation.

With regard to the monofilament suture materials analyzed, it was observed that chromic gut induced tissue necrosis and more granulation tissue formation, thus corroborating the findings in the literature [29]. These results were found due to the presence of chromium salt on its surface, which is also associated with other effects, such as disturbances in the transmission of nervous pulses [30], pain [31] and lithogenesis [32].

In the surface morphology analysis on the 2nd day of the experiment, when the microscopic examination showed a larger necrosis area, chromic gut presented the adhesion of many cells. Beginning on the 3rd day, when the chromium coating was absorbed and the amount of cells on the surface decreased, the beginning of granulation tissue formation was observed. On the 7th day, the granulation tissue was still present but the absence of cells and chromium salt on the surface of the material was noted. These findings substantiate the phlogogen potential of chromium coating, which also performs a physical action in inflammation induction. The presence of chromium salt on the chromic gut surface is also responsible for the tissue drag attributed to this material during its passage through tissue [8]. The attenuation of the line on the chromic gut surface indicates that the material is experiencing dissolution within the tissue [14] resulting from enzymatic collagen degradation.

\section{Conclusion}

In this study, it was observed that suture materials induced differentiated tissue reactions, suggesting the need for individualized indications for each material. Thus, poliglecaprone 25 would be suitable for sutures in general, because of its great physical and biological properties. Polydioxanone would be the appropriate material for areas that require larger tensile strength, considering the few alterations undergone by the material. Chromic gut and irradiated polyglactin 910 induced stronger tissue reaction-the latter with multinucleated giant cells. As such, the indications of these two materials should be restricted to non-infected areas and to those that do not require aesthetics or tension resistance.

\section{References}

1. K. K. OUtlaw, R. Vela and P. O'LeARY,Am. Surg. 64 (1998) 348.

2. A. RUNK, S. W. Allen and E. A. MAhAfFey, Vet. Surg. 28 (1999) 466.

3. K. TOMIHATA, M. SUZUKI, T. OKA and Y. IKADA, Polym. Degrad. Stability 59 (1998) 13.

4. F. H. GRECA, J. C. D. REPKA, Z. A. SOUZA-FILHO, C. F. R. ARAÚJO, S. O. IOSHII, R. STROBEL and A. L. PACHECO, Acta. Cir. Bras. 11 (1996) 179.

5. J. J. BLAKER, S. N. NAZHAT and A. R. BOCCACCINI, Biomaterials 26 (2004) 1319.

6. L. K. McCAUL, J. B AGG and W. M. JENKINS, Br. J. Oral Maxillofac. Surg. 38 (2000) 328.

7. L. ZHANG, C. C. CHU and I. LOH, J. Biomed. Mater. Res. 27 (1993) 1425.

8. R. CHANDRA and R. RUST Gi, Progr. Polym. Sci. 23 (1998) 1273.

9. R. S. BEZWADA, D. D. JAMIOLJOWSKI, I. LEE, V. ARGWAL，J. PERSIVALE, S. TRENKA BETIN, M. ERNETA and J. SURY ANDEVARA, Biomaterials 16 (1995) 1141.

10. E. G. D. BOLAND, B. D. COLEMAN, C. P. BARNES, D. G. SIMPSON, G. E. WNEK and G. L. BOWLIN, Acta Biomaterialia 1 (2005) 115.

11. M. A. SABINO, S. GONZÁLEZ, L. MÁRQUEZ and J. L. FEIJ OO, Polym. Degrad. Stability 69 (2000) 209.

12. W. C. HSIAO, K. C. YOUNG, S. T. WANG and P. W. LIN, World J. Surg. 24 (2000) 747.

13. K. H. LEE and C. C. CHU, J. Biomed. Mater. Res. 49 (2000) 25.

14. T. OKADA, T. HAYASHI and Y. IKADA, Biomaterials 13 (1992) 448.

15. E. O. KEHINDE, Y. ALI, AL-HUNAYAN and A. H. M A HMOUD, Transplant. Proceed. 32 (2000) 1917.

16. V. HARSICI, K. LEWANDROWSKI, J. D. GRESSER, D. L. WISE and D. J. TRANTOLO, J. Biotech. 86 (2001) 135.

17. M. A. Q. R. FORTES and M. V. SADI, Rev. Col. Bras. Cir. 23 (1996) 83.

18. G. MOLEA, F. SCHONAUER, G. BIFUlCO and D. D' ANGELO, Br. J. Plastic. Surg. 53 (2000) 137.

19. G. A. DeNARDO, N. O. BROWN, S. TRENKABREntin and S. M. MARREt A, J. Am. Anim. Hosp. Assoc. 32 (1996) 164.

20. J. KIRPENSTEIJN, R. J. MAARSCHALKERWEERD, J. P. KOEMAN and H. S. KOOISTRA, Vet. Quart. 19 (1999) 20.

21. N. TERADA, L. M. BUJRSTEN, D. DOHI and G. LUNDB OR G, Scand. J. Plastic. Reconstr. Hand Surg 31 (1997) 31. 
22. P. SCHERMAN, G. LUNDBORG, M. KANJE and L. B. DA HLIN, Scandinavian J. Plastic. Reconstr. Hand Surg. 34 (2000) 1.

23. C. R. UFF, A. D. SCOTT, G. POCKLEY and R. K. S. PHILliPS, Biomaterials 16 (1995) 355.

24. F. B. NIESSEN, P. H. M. SPAUWEN and M. KON, Ann Plastic Surg 39 (1998) 254.

25. R. AMATO, B. MARCELli, M. OREFICCI, L. MASTROIANNI and M. VERGNANi, Minerva Stomatol. 40 (1991) 163.

26. J. B. TRIMBOS, A. NIGGEBRUGGE, R. TRIMBOS and E. J. C. VAN RUSSEL, Eur. J. Surg. 161 (1995) 319.
27. B. GUYURON and C. VA U GHAN, Plastic. Reconstr. Surg. 98 (1996) 817.

28. C. J. IVANOFF and G. WIDMAR K, Clin. Implant. Dent. Relat. Res. 3 (2001) 57.

29. M. Chalhoub, N. C. PRestes, M. D. LOPES, N. S. ROCHA, I. A. THOMAZINI-SANTOS and M. J. Mendes-Gi Annini, J. Venom. Anim. Toxins 6 (2000) 220.

30. J. XU, C. H. POLLOCK and K. C. KAJANDER, Pain 64 (1996) 503-509.

31. I. ROB INS ONA and T. F. MEER T A, Neuroscience Letters 373 (2005) 125.

32. J. LaB A GNARA JR, Ear Nose Throat J. 74 (1995) 409. 